\title{
A REVERSIBLE PHASE TRANSITION IN FERRIC FERRICYANIDE
}

\author{
K. TENNAKONE \\ Department of Physics, University of Rubuna, Matara, Sri Lanka.
}

(Date of receipt : 18.07.86)

(Date of acceptance : 09.09.86)

\begin{abstract}
Solid ferric ferricyanide which is dark green in colour undergoes reversible transition into a yellowish white form at $340^{\circ} \mathrm{C}$. This phase change is also associated with a transition in the electrical conductivify. It is suggested that in the green form carbon in $\mathrm{CN}$ is linked to high spin $\mathrm{Fe}^{37}$ and in the yellow form this linkage is reversed.
\end{abstract}

\section{Introduction}

The study of solid state structure, electrical transport and other physical and chemical properties of Prussian Blue and related heavy metal hexacyanides have attracted much attention. $1,2,12,13$ In all these compounds the metallic ions form a face-centred cubic lattice joined along the edges by $\mathrm{CN}^{-}$ ions. In heavy metal ferricyanides (ferrocyanides) carbon is almost always coordinated to ferric (ferrous) ion and nitrogen to the other metal ion. $7,8,17$ Linkage isomerisms that reverse these bonds sometimes occur at higher temperatures. $4,9,10$ Brick red ferrous chromocyanide undergoes an irreversible transition into green chromium (III) ferrocyanide at $\sim 100^{\circ} \mathrm{C} .4,9,10$

We have observed an even more peculiar form of reversible phase transition in Berlin Green (Ferric Ferricyanide, $\mathrm{Fe}^{\mathrm{III}}\left(\mathrm{Fe}^{\mathrm{III}}(\mathrm{CN})_{6}\right)$. This material which is dark green in colour transforms reversibly into a yellowish white form at $340^{\circ} \mathrm{C}$. The phase change is also associated with a transition in the electrical conductivity. At $340^{\circ} \mathrm{C}$, conductivity decreases by a factor of $\checkmark 10^{3}$, when the material transforms from green to the yellowish white form.

\section{Experimental}

Berlin green was prepared by double decomposition of a ferric salt and potassium ferricyanide (Analar grade reagents were used). The polycrystalline powder of $\mathrm{Fe}^{\mathrm{III}}\left(\mathrm{Fe}^{\mathrm{III}}(\mathrm{CN})_{6}\right)$ separates out when the mixture is boiled and kept standing for several hours. The precipitate was separated, washed and boiled with $75 \% \mathrm{HNO}_{3}$ to convert any Prussian Blue present as an impurity into Berlin Green. (Berlin Green is unusually stable towards 
oxidation and remain completely unaffected even upon prolonged boiling with concentrated $\mathrm{HNO}_{3}$, all the other ferri- and ferro- cyanides decompose under these conditions). The precipitate was filtered off, washed with double distilled water and dried in vacuum at $200^{\circ} \mathrm{C}$.

All attempts to make single crystals of Berlin Green by diffusion or gel methods were unsuccessful. Consequently conductivity measurements were carried out with compacted pellets. The powder was pressed between stainless steel electrcides in a glass tube (diameter $\sim 0.8 \mathrm{~cm}$ ) to a pressure of 800 psi until a pellet (length $\sim 0.5 \mathrm{~cm}$ ) was formed. The ends of the tube were sealed expoxy resin, the sample was immersed in a thermostatic oil bath and d.c. conductivity was measured using a resistance meter (Computing Digital Multimeter, Takeda Riken 6877). The I-V characteristics were found to be linear and no polarization effects were detected. Again a.c. measurements gave similar results.

The transition temperature was noted by heating the powder in an evacuated glass tube.

\section{Discussion}

Figure 1 shows a plot of $\log \sigma$ vs $\mathrm{T}^{-1}$. It is seen that conductivity rapidly increases until the transition temperature is reached. At this temperature there is an abrupt change in conductivity. The conductivity in the second phase (ie, the yellow form) is smaller by a factor $\sim 10^{3}$. Transition is completely reversible, no hysteresis effects are seen.

In Berlin Green $\mathrm{CN}^{-}$. ions are bridged between two ferric ions and the observed transition could not be due to a linkage isomerism of the familiar type. It is very likely that the transition results from the following mechanism. In most hexacyanoferrates, the ferric ions that are linked to carbon have high spin whereas the ferric ions linked to nitrogen have low spin ${ }^{16}$ One could expect that in the green form of $\mathrm{Fe}^{\mathrm{III}}\left(\mathrm{Fe}^{\mathrm{II}}(\mathrm{CN})_{6}\right)$ the $\mathrm{Fe}^{3+}$ attached to carbon is high spin and $\mathrm{Fe}^{3+}$ attached to nitrogen is low spin (Figure 2). Above the transition temperature this gets reversed, ie, $\mathrm{Fe}^{3+}$ attached to carbon and nitrogen have low and high spin respectively (Figure 2). Mossabuer and IR spectroscopy could establish whether the proposed mechanism is responsible for the observed phase transition. Unfortunately we did not have the facilities to carry out these experiments. Again we are not in a position to explain the detailed features in the temperature variation of conductivity, ie, why the conductivity decreases with increase of temperature in the yellow phase after the initial increase (ie, semiconductor to metal type transition). Measurements with single crystals are essential for making theoretical interpretations. 


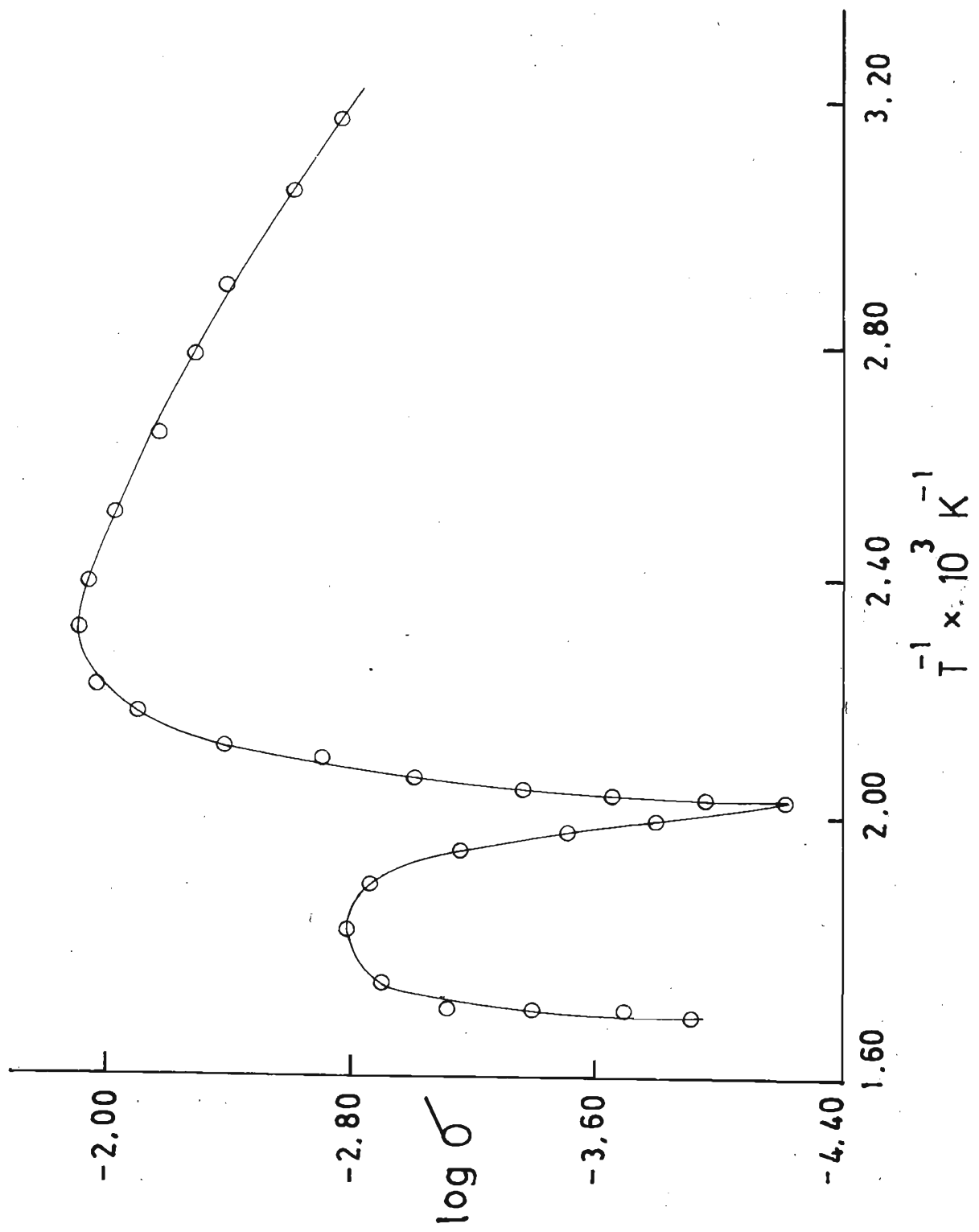

Figure 1. Plot of $\log \sigma$ vs $\mathrm{T}^{-1}\left(\sigma\right.$ in $\left.\Omega^{-1} \mathrm{~m}^{-1}\right)$ 


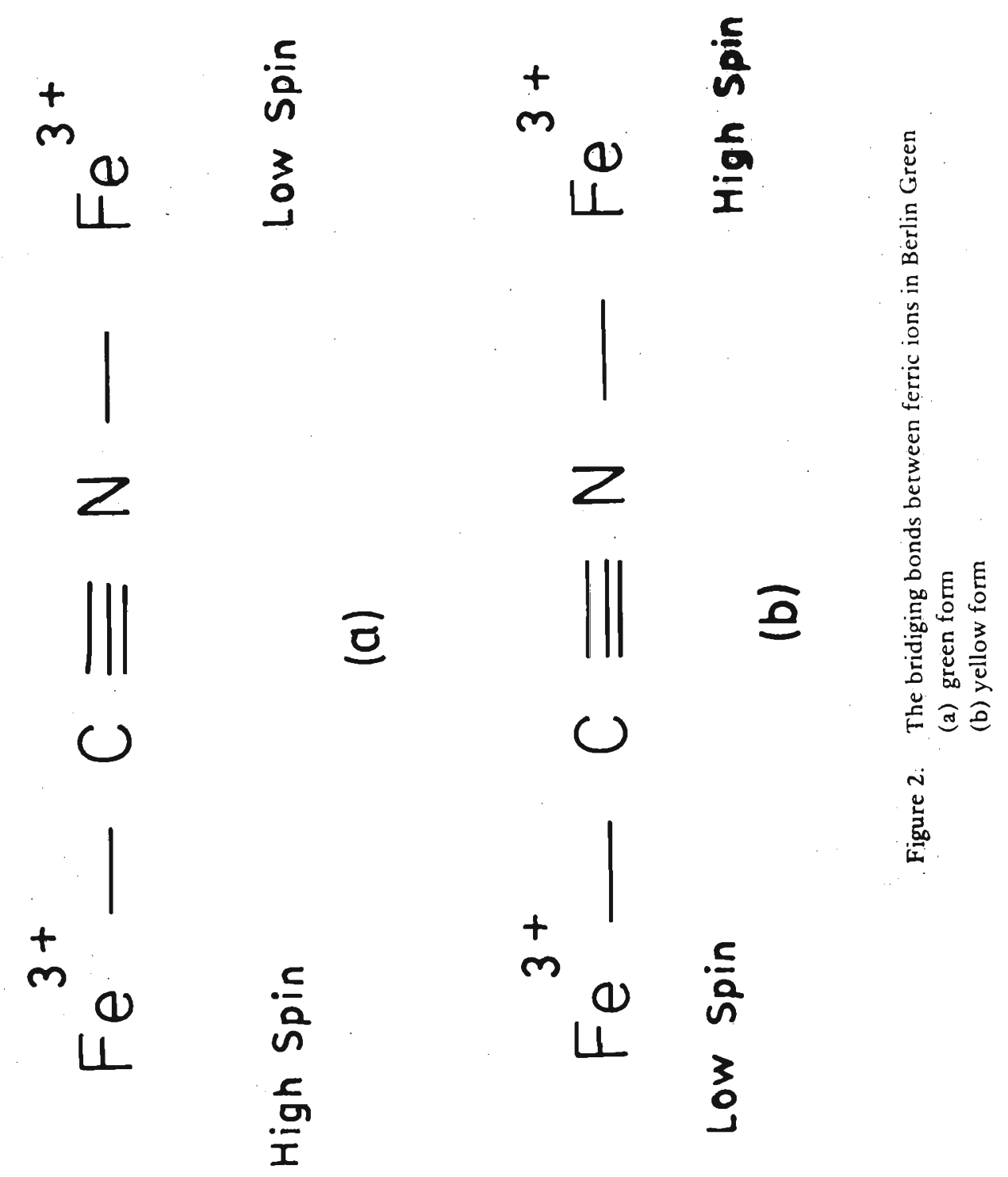




\section{References}

1. AYERS, J.B. \& WAGGONER, W.H. (1969) J. Inorg. Nucl. Chem., $31: 2045$.

2. AYERS, J.B. \& WAGGONER, W.H. (1971) J. Inorg. Nucl. Chem., 33 : 721.

3. BONNETTE, A.K. \& ALLEN, J.E. (1971) J. Inorg. Chem., $10: 1613$.

4. BROWN, D.B., SHRIVER, D.F. \& SCHWARTZ, L.H. (1968) Inorg. Chem., 7: 77.

5. GANGUli, S. \& BHATtACHARYA, M. (1983) J. Chem. Soc, Faraday Trans. I $79: 1513$.

6. INOUE, H. \& YANAGISAWA, S. (1974) J. Inorg. Nucl. Cbem., $36: 1409$.

7. LUDI; A. \& GUDEL, M.U. (1973) Struct. Bonding, $14: 1$.

8. LUDI, A., GUDEL, H.U. \& RUEGG, M. (1970) Inorg. Chem., $9: 2224$.

9. SHRIVER, D.F. (1962) J. Am. Chem. Soc., $84: 4610$.

10. SHRIVER, D.F., SHRIVER, S.A. \& ANDERSON, S.E. (1965) Inorg. Chem., 4 : 725 .

11. TENNAKONE, K. (1983) J. Chem. Phys. 78 (6): 3343.

12. TENNAKONE, K. (1984) J. Solid State Chem. $52: 217$.

13. TENNAKONE, K. Pbys. Rev., B $29: 5951$.

14. TENNAKONE, K. \& DHARMARATNA, W.G.D. (1983) J. Pbys. C, $16: 5633$.

15. VERTES, A., KOREEZ, L. \& BURGER, K. (Elsevier, Amsterdam 1979) Mossabuer Spectroscopy.

16. WELLS, A.G. (Oxford 1975) Structural Inorganic Chemistry, (2). 